\title{
Non-isothermal sintering of powdered vitrified composites. A kinetic
} model.

\author{
J.L. Amorós ${ }^{a, b}$, E. Blasco ${ }^{b}, A . M^{2}$ Mono $^{a, b}$, E. Zumaquero ${ }^{b}$, C. Feliua, b \\ a Department of Chemical Engineering, Universitat Jaume I, Campus Universitario Riu Sec, \\ Castellón, 12006, Spain. \\ b Instituto de Tecnología Cerámica - Asociación de Investigación de las Industrias Cerámicas, \\ Castellón, 12006, Spain.
}

\begin{abstract}
This report sets out the results obtained on studying the sintering process of glass-zircon composites, analysing the microstructural changes that developed on modifying zircon content. The sintering of composites with moderate zircon contents only developed via particle rearrangement by viscous flow. In contrast, at high zircon contents, the zircon solutionreprecipitation process was also required. A kinetic model was developed and validated that describes the effect of the heating rate and zircon volume fraction on the composite degree of non-isothermal sintering progress associated with particle rearrangement by viscous flow.
\end{abstract}

\section{Keywords}

Ceramic composites; sintering; kinetic model; glass viscosity.

\section{Introduction}

The key to an economically successful industrial waste vitrification process lies in obtaining glassy material that can be used in manufacturing products with greater added value. Glazes and GMCs obtained by powder technology and sintering are good examples of this approach. In fabricating these materials, particularly in the case of glazes, it is essential to achieve zero apparent porosity and low closed porosity. At high rigid particle (zircon, alumina, etc.) contents, $\phi$, this requirement is difficult to attain, even when the glass matrix exhibits low viscosity and does not devitrify during sintering of the material.

The sintering of composites (GMCs) has been studied by different researchers. Scherer developed a theoretical model based on the continuum theory of sintering [1][2], though it is 
only appropriate for $\phi<0.15$. Bordia and Raj [3] considered sintering kinetics of order 1 , the rate constant (or time constant) depending on $\phi$; however, this does not work appropriately for moderate values of $\phi$ either. Müller et al. [4] developed a sophisticated and complex kinetic model, which requires identical glass and inclusion particle size. This only works appropriately for $\phi<0.35$.

The present study was undertaken to develop a kinetic model describing the effect of the heating rate, $\beta$, and zircon volume fraction on the composite degree of sintering progress, $\alpha$, in a non-isothermal process when the solution-reprecipitation mechanism did not occur. Zircon was used as rigid inclusion, owing to its low glass solubility and widespread use in glazes, in addition to having a standard glass matrix (SRM 717a) [5], with a known viscosity curve and wide firing range, and not devitrifying. The particle size distributions of each material were similar to those used in the glaze industry.

In composite sintering via particle rearrangement by viscous flow, the process rate is described by the equation:

$$
\frac{d \alpha}{d T}=k(T) f(\alpha)
$$

where $f(\alpha)$ is the sintering model (which expresses the influence of $\alpha$ on the process rate) and $k(T)$ is the rate constant. Assuming the effect of temperature on the process rate is given by the effect of temperature on the inverse of glass matrix viscosity, $k(T)$ must be related to the VogelFulcher-Tamman (VFT) equation, yielding:

$$
k(T)=A \exp \left(-\frac{B}{T-T_{0}}\right)
$$

where $B=5495 \mathrm{~K}$ and $\mathrm{T}_{0}=421 \mathrm{~K}$ are the values of the VFT equation parameters for the viscosity of this glass according to the NBS [5], and A is the pre-exponential factor.

For a process at constant-rate heating, $\beta$, equations (1) and (2) yield:

$$
\left(\frac{d \alpha}{d T}\right)=\frac{A}{\beta} \exp \left(-\frac{B}{T-T_{0}}\right) f(\alpha)
$$


Separating variables and integrating yields the integral form of the sintering model, $g_{i}(X)$, and its relation to temperature, which depends on the type of approximation used to solve the temperature integral. Using the Murray and White approximation [6], one obtains:

$$
g(\alpha)=\int_{0}^{\alpha} \frac{d \alpha}{f(\alpha)}=\frac{A}{\beta} \int_{0}^{T} \exp \left(-\frac{B}{T-T_{0}}\right) d T=\frac{A\left(T-T_{0}\right)^{2}}{\beta B} \exp \left(-\frac{B}{T-T_{0}}\right)
$$

As this sintering process can be described by the Avrami-Erofeev model [7], with a value of $n$ between 0 and 1 , in integrated form, this yields:

$$
g(\alpha)=[-\ln (1-\alpha)]^{\frac{1}{n}}
$$

From equations (4) and (5), for the degree of sintering process progress, $\alpha$, via particle rearrangement by viscous flow, one obtains the expression:

$$
\alpha=1-\exp \left\{-\left[\left(\frac{A}{\beta}\right)\left(\frac{\left(T-T_{0}\right)^{2}}{\beta}\right) \exp \left(-\frac{B}{\left(T-T_{0}\right)}\right)\right]^{n}\right\}
$$

\section{Materials and methods}

An industrial zircon powder and a standard non-devitrified borosilicate glass (SRM 717a) powder, obtained by wet milling, both having industrial particle size distributions (table 1), were used to prepare mixtures at different zircon volume fractions, $\phi \leq 0.65$, by the wet method. Cylindrical test pieces, about $5 \times 3 \mathrm{~mm}$, were pressed at 50MPa. The sintering and melting curves were determined from the test piece silhouettes by heating microscopy (HSM), at different heating rates ( $\beta=0.5$ to $60 \mathrm{~K} / \mathrm{min}$ ). The degree of sintering progress, $\alpha$, was calculated from:

$$
\alpha=\frac{\epsilon_{\mathrm{A}}}{\epsilon_{\mathrm{A}, \max }}=\frac{\ln \left(\mathrm{S}_{0} / \mathrm{S}\right)}{\ln \left(\mathrm{S}_{0} / \mathrm{S}_{\min }\right)}
$$

where $\in \mathrm{A}$ and $\in \mathrm{A}$, max are the instantaneous and maximum surface strain, respectively, (similar to surface shrinkage) and $S_{0}, S$, and $S_{\min }$ are the initial, instantaneous, and minimum silhouette surface areas, respectively. The fixed viscosity points of the glass were determined from the shape of the HSM test piece silhouettes [8].

Table 1. Values of $d_{90}, d_{50}$, and $d_{10}$ for the glass and zircon powders, corresponding to less than $90 \%, 50 \%$, and $10 \%$ by volume, respectively, of the particles. 


\begin{tabular}{llll}
\hline Powder & $\mathbf{d}_{90}(\mu \mathrm{m})$ & $\mathbf{d}_{50}(\mu \mathrm{m})$ & $\mathbf{d}_{10}(\mu \mathrm{m})$ \\
\hline Glass & 17.7 & 5.6 & 1.5 \\
\hline Zircon & 3.4 & 1.5 & 0.5 \\
\hline
\end{tabular}

Cylindrical test pieces, about $2 \times 2 \mathrm{~cm}$, obtained by slip casting, were subjected to constant rate heating in a laboratory furnace. These pieces were characterised by mercury porosimetry, scanning electron microscopy (SEM) (with EDS and image analysis), and X-ray diffraction (XRD) to monitor the development of the microstructural characteristics of the different materials with sintering progress and to study the zircon solution-reprecipitation process. The pore size distributions (PSDs) were fitted to log-normal distributions. D16 corresponds to the statistical value of the average plus the standard deviation of the normal distribution. This was considered representative of the coarse pore fraction. $D_{84}$, representative of the fine pore fraction, was the statistical value of the average minus the standard deviation of the normal distribution.

Zircon grain size distributions were measured by SEM micrograph analysis. The experimental results were fitted to the Weibull equation.

\section{Results and discussion}

The glass-temperature viscosity curve, calculated from the fixed viscosity points fitted equation VFT (2) very well (fig. 1a). As $\phi$ increased, the sintering temperature range widened and shifted to higher temperatures, the effect increasing as the zircon content, $\phi$, rose. At $\phi<0.43$, the sintering curves were sigmoidal, analogous to those of non-devitrifying glasses. The curve only ceased to exhibit this shape at $\phi \geq 0.53$, as the solution-reprecipitation mechanism had already become important (fig. 1a). Indeed, at values exceeding $1000^{\circ} \mathrm{C}$, the zircon mass fraction $\left(w_{z}\right)$ decreased and its average size, GM, and size distribution uniformity index, $M$, increased with temperature (fig. 1b). At $\phi \leq 0.32$, little closed porosity, $\varepsilon_{\text {closed, }}$ developed and only did so at temperatures close to maximum densification (fig. 1c). In contrast, at $\phi \geq 0.53$, $\varepsilon_{\text {closed }}$ started to develop when true porosity, $\varepsilon_{\text {true, }}$ was still high, $\varepsilon_{\text {closed }}$ being significant at maximum densification (fig. 1c). All composites exhibited large pore growth ( $D_{16}$ increased) and progressive elimination of small pores ( $D_{84}$ increased) (fig. $\left.1 d\right)$. This phenomenon, which became more pronounced as zircon content rose, stemmed from the differential shrinkage of different regions of the material 
owing to greater heterogeneity in the nature and type of interparticle (glass-glass, glass-zircon, and zircon-zircon) contacts.
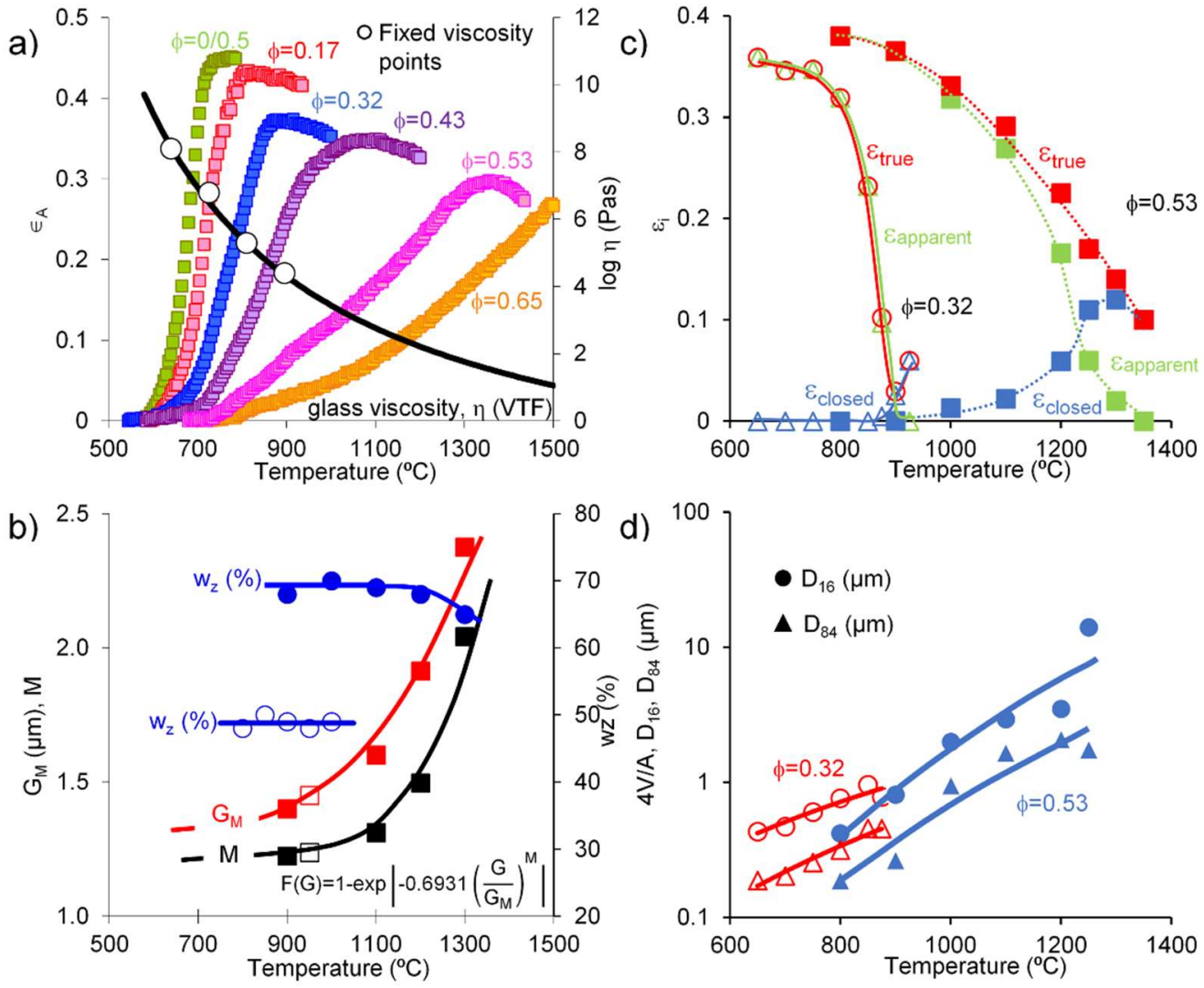

Fig. 1. Evolution of composite characteristics with temperature. Heating rate, $\beta=5 \mathrm{~K} / \mathrm{min}$ : a) surface strain (sintering curves) at different zircon volume fractions, $\phi$; glass viscosity, fitted to the VFT (equation (2)); and fixed viscosity points according to Pascual et al. [8]; b) Weibull parameters, $G_{M}$ and $M$, of the zircon grain size distributions and zircon mass fraction, $\left.w_{z} ; c\right)$ apparent ( $\left.\varepsilon_{\text {apparent }}\right)$, closed ( $\left.\varepsilon_{\text {closed }}\right)$, and true (Etrue) porosity; and d) statistical values of intrusion diameters, $D_{16}$ and $D_{84}$. In figs. $\left.\left.1 b\right), c\right)$, and d), empty symbols: $\phi=0.32$ and full symbols: $\phi=0.53$. SEM micrographs (fig. 2) confirmed good mixing of both powders. As sintering progressed, the number of pores decreased, pore size grew, and the pores became less irregular. At maximum densification temperature, the pores had closed, were quasi-spherical, and their walls were mainly made up of zircon particles. This effect was more pronounced as zircon content rose. Zircon size and shape only changed at $\phi \geq 0.53$ and high temperatures. 
a)
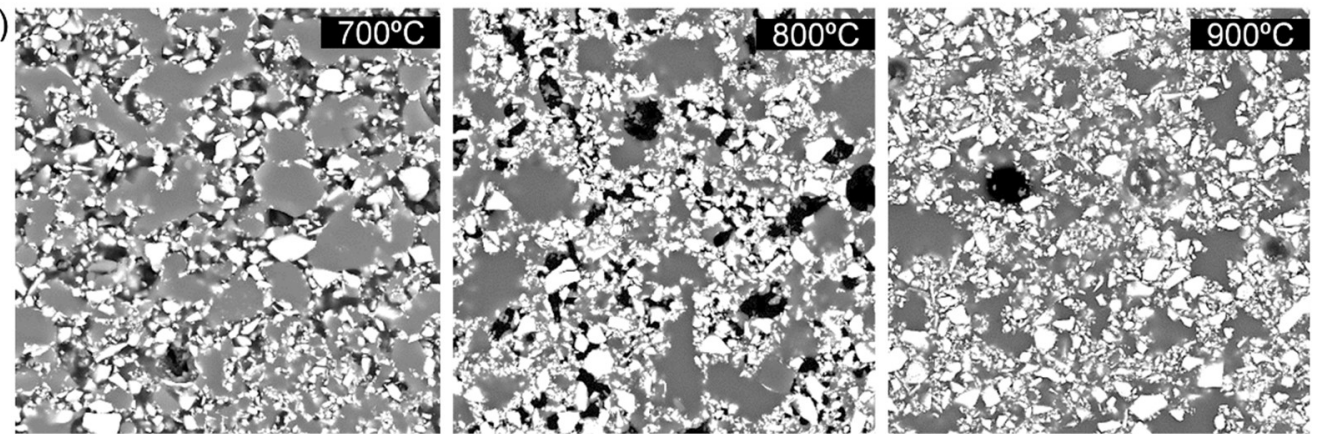

b)
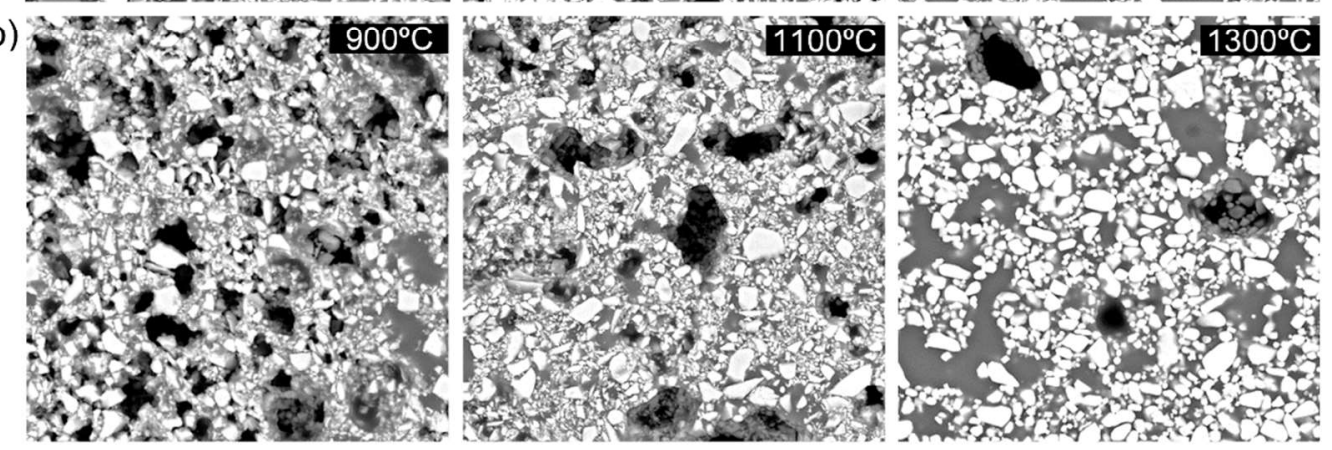

$30 \mu \mathrm{m}$

Fig. 2. SEM micrographs of the composites fired at different maximum temperatures, heating at $\beta=5 \mathrm{~K} / \mathrm{min}:$ a) $\phi=0.32$ and b) $\phi=0.53$.

As zircon content decreased, maximum relative density, $\rho_{\max }$, and maximum attainable surface strain, $\in_{A, \max }$ (similar to shrinkage) in the composite decreased (fig. 3a), owing to greater development of pores relating to formation of zircon clusters (fig. $2 \mathrm{~b}$ at $1300^{\circ} \mathrm{C}$ ). Indeed, the reduced maximum surface strain, $\Delta \in_{\mathrm{A}, \max }$, (fig. 3a ) was calculated from:

$$
\Delta \epsilon_{\mathrm{A}, \max }=1-\frac{\epsilon_{\mathrm{A}, \max }}{\epsilon_{\text {glass,max }}}
$$

where $\epsilon_{\text {glass, max }}$ is the glass maximum surface strain. The reduced densification from zircon addition (equation 8), attributed to residual pores stabilised by zircon clusters, was similar to that obtained by Eberstein [9].

Kinetic parameters $n$ and A were obtained by fitting the experimental sintering curves $(\alpha-T)$ to equation (6), for $\phi \leq 0.43$, and only the first stretch of the curve for $\phi=0.53$. $n$ decreased linearly with $\phi$ (fig. 3b), indicating that the sintering rate dropped with process progress, $\alpha$, as zircon content rose. The pre-exponential factor, A, decreased considerably with $\phi$ (fig. 3b), because the number of glass interparticle contacts also decreased and glass-zircon system viscosity 
increased. The fit of the experimental results to equation (6) (figs. 3c and d) was very good. At $\phi \geq 0.53$, the fit was also good, though only for the first stretch of the curve in which sintering developed via particle rearrangement by viscous flow.
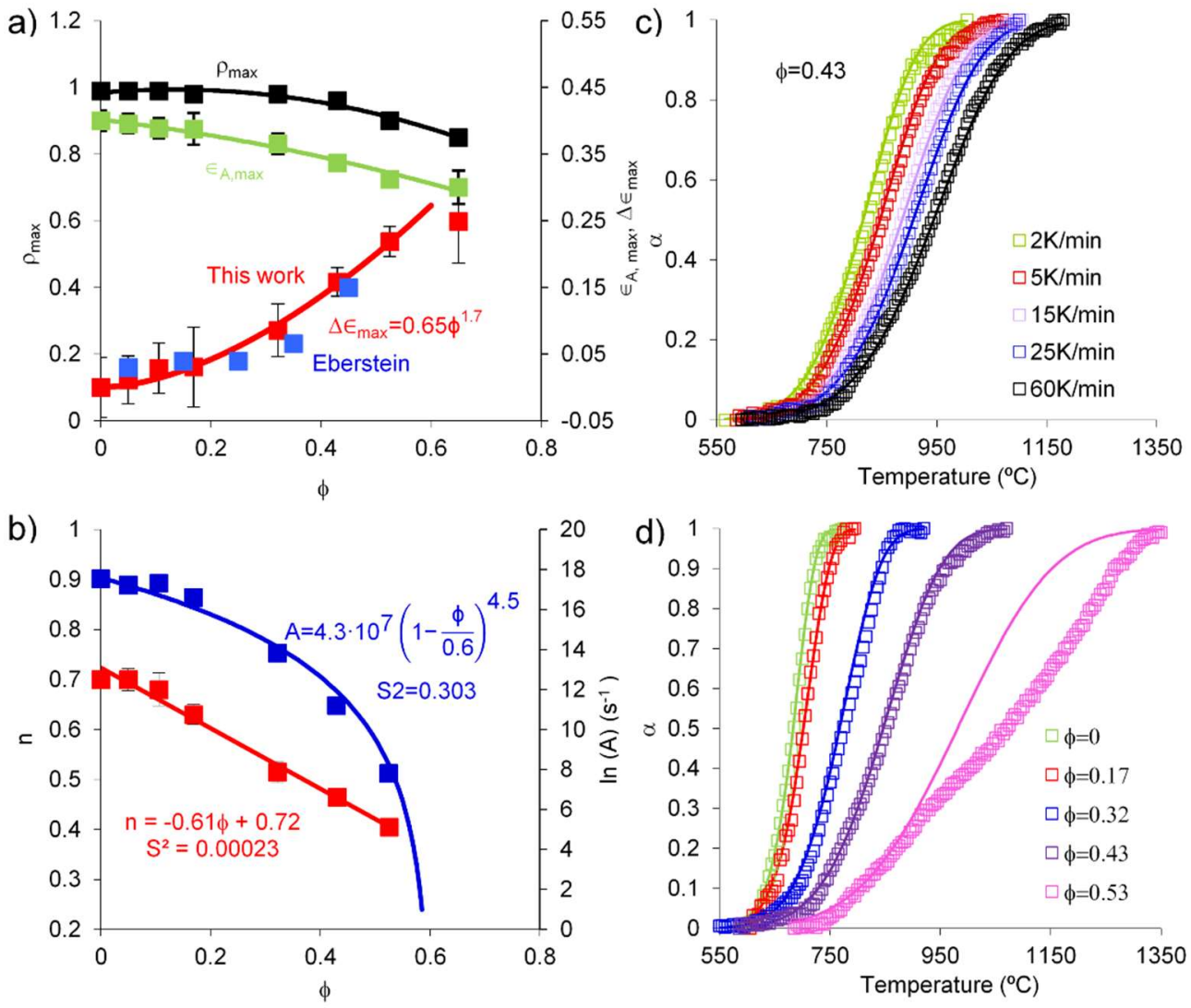

Fig. 3. Influence of zircon volume fraction, $\phi$, on: a) maximum relative density, $\rho_{\max }$, maximum surface strain, $\in_{\mathrm{A} \text {,max }}$, and reduced maximum surface strain, $\Delta \in_{\mathrm{A} \text {,max, }}$ (equation (8)) (red squares: this study; blue squares: Eberstein's data [9]), and on b) kinetic parameters $n$ and $A$. Sintering curves of composites. Comparison of experimental data and values calculated from equation (5) and parameters of fig. 3b): c) effect of heating rate ( $\phi=0.43)$ and d) effect of zircon volume fraction, $\phi$, $(\beta=5 \mathrm{~K} / \mathrm{min})$.

\section{Conclusions}

As apparent porosity decreased in the initial and intermediate sintering stages, the average size of the generally irregular pores increased. This phenomenon, together with the formation of closed porosity and the minimum attainable porosity in the composite, depended on zircon content. The zircon solution-reprecipitation process started at high temperatures and/or long 
treatment times, so that it only contributed to the densification of composites with high zircon content. A kinetic model was developed that appropriately describes the effect of heating rate and zircon content on sintering process progress via particle rearrangement by viscous flow. The effect of temperature on the process rate was verified to be the effect that temperature had on glass matrix viscosity.

\section{Acknowledgements}

This study was co-funded by the ERDF Operational Programme for the Valencia Region and the Valencian Institute for Business Competitiveness (IVACE).

\section{References}

[1] G. W. Scherer. J. Am. Ceram. Soc. 70[10] (1987) 719-725.

[2] G. W. Scherer. J. Am. Ceram. Soc. 70[10] (1988) 447-448.

[3] R. K. Bordia and R. Raj. J. Am. Ceram. Soc. 69 (1986) C55-C57.

[4] R. Müller, M. Eberstein, S. Reinsch, W. A. Schiller, J. Deubener and A. Thiel. Phy. Chem. Glasses - Eur. J. Glass Sci. Technol. Part B 48[4] (2007) 259-266.

[5] National Institute of Standards and Technology, Certificate Standard Reference Material 717a Borosilicate Glass.

[6] P. Murray and J. White. Trans. Brit. Ceram. Soc. 54 (1955) 204-264.

[7] I. Gustoz, S. Todorova and N. Jordanov. Bulg. Chem. Comm. 42[2] (2010) 79-102.

[8] M. J. Pascual, A. Duran, M. O. Prado. Phys. Chem. Glasses. 46[5] (2005) 512-520.

[9] M. Eberstein, S. Reinsch, R. Müller, J. Deubener, W. A. Schiller A. J. Eur. Ceram. Soc. 29[12] (2009) 2469-2479. 